\title{
Verificação da dispersão de respingos durante o trabalho do cirurgião-dentista
}

\author{
José Augusto César Discacciati, ${ }^{1}$ Herbert Haueisen Sander, ${ }^{1}$ \\ Lia Silva de Castilho ${ }^{1}$ e Vera Lúcia Silva Resende ${ }^{1}$
}

RESUMO Todas as pessoas envolvidas em um atendimento odontológico estão sujeitas à contaminação por bactérias, vírus e fungos que podem causar diversas enfermidades, dentre as quais se destacam a hepatite, a tuberculose, o herpes e a AIDS. Sabe-se que, durante um atendimento, há possibilidade de ocorrer dispersão de respingos e aerossóis contendo microrganismos patogênicos. No entanto, algumas clínicas odontológicas são projetadas com vários consultórios no mesmo ambiente, sem divisórias entre eles. O objetivo deste trabalho foi verificar qual o alcance dos respingos provenientes da utilização de seringa tríplice e turbina de alta rotação em cinco atendimentos clínicos simulados em uma clínica de atendimento coletivo, considerando que estes respingos podem conter saliva e sangue do paciente. Para isso, anilina de diferentes cores (rosa, azul, amarela, verde e marrom) foi adicionada à água do reservatório de cada um dos cinco equipamentos. Todo o ambiente físico, assim como a roupa do operador e do paciente, foram cobertos com papel crepom branco. Constatou-se grande concentração de respingos sobre as cadeiras, sobre o operador, sobre o piso, cadeiras vizinhas e bandejas clinicas das unidades vizinhas. A distância máxima atingida pelos respingos foi de 1,82 $\mathrm{m}$, medindo-se a partir do ponto correspondente à boca do paciente. Durante um atendimento real, coletivo e simultâneo nesta clinica, as cadeiras vizinhas e seus respectivos pacientes e operadores, bem como as bandejas clínicas contendo instrumental esterilizado situam-se dentro da área de abrangência dos respingos. Portanto, existe uma possibilidade real de ocorrer contaminação cruzada, havendo necessidade de colocação de barreiras físicas entre os equipamentos. O estudo evidenciou também a necessidade de proteção de toda a face, o corpo, o cabelo e os braços do operador, uma vez que estas foram regiões muito atingidas pelos respingos.

Dentre os vários riscos a que estão sujeitos os profissionais de saúde e seus pacientes, está o risco de infecção cruzada, ou seja, transmissão de agentes infecciosos dentro do ambiente clínico. Esta transmissão pode se dar através de contato pessoa-pessoa, pelo ar ou através de objetos contaminados

\footnotetext{
Departamento de Odontologia Restauradora, Faculdade de Odontologia da Universidade de Minas Gerais, Belo Horizonte, Brasil. Correspondência e pedidos de separatas devem ser enviados para José Augusto César Discacciati no seguinte endereço: Avenida do Contorno 9787, sala 16, Barro Preto, CEP 30110-130, Belo Horizonte, Minas Gerais, Brasil.
}

(1). Apesar do problema sempre ter existido, os profissionais de saúde nem sempre estiveram conscientes e dispostos a seguir os passos necessários para minimizar os riscos para si próprios, para o pessoal auxiliar e para os pacientes (2).

A emergência da epidemia da síndrome de imunodeficiência adquirida (AIDS), no início da década de 80, fez despertar uma consciência maior por parte das comunidades de saúde para o perigo da transmissão ocupacional de agentes infecciosos. Este fato proporcionou um avanço na adoção de medidas de biossegurança e o assunto se tornou uma das principais preocupações para a prática médico-odontológica (2-4). Mesmo assim, a infecção cruzada continua representando um risco para profissionais e pacientes (5) e, provavelmente, ocorre com mais freqüência do que a literatura registra, em parte devido ao longo período de incubação de algumas doenças, como a hepatite, e também devido ao grande número e variedade de contatos extra consultório (6).

A utilização de turbinas de alta rotação, raspadores ultra-sônicos e seringas de ar/água provocam a formação de aerossol. Por aerossol entende-se 
qualquer volume de ar contendo partículas sólidas ou líquidas em suspensão. Estas partículas podem permanecer flutuando por um período curto ou longo, dependendo de seu tamanho, que pode variar entre 0,001 e 10000 $\mu \mathrm{m}$. As partículas de aerossol com diâmetros maiores do que $100 \mu \mathrm{m}$ recebem o nome de respingos e, devido à força gravitacional, se assentam mais rapidamente do que as partículas menores (1). Microrganismos patogênicos que eventualmente estejam presentes no sangue e saliva dos pacientes podem ser transportados pelo aerossol e infectar outras pessoas, causando doenças como gripe, resfriado comum e tuberculose $(1,5,7)$.

A carga microbiana média suspensa no ar aumenta em mais de três vezes durante um atendimento odontológico, quando comparada com o período anterior ao início do atendimento (8). As partículas suspensas no ar durante e após os atendimentos odontológicos podem penetrar através do trato respiratório e membranas conjuntivas do cirurgião-dentista, de seus assistentes e também dos pacientes que serão atendidos posteriormente $(1,8)$. Além disso, alguns procedimentos podem dispersar partículas agudas de tecido dental, cálculo e material restaurador com considerável força. Pesquisas têm demonstrado que partículas maiores do que $0,1 \mathrm{~mm}$ podem ser dispersadas a distâncias maiores do que $6 \mathrm{~m}$, numa velocidade de 50 a 60 $\mathrm{km} / \mathrm{h}$. Nesse caso, tanto os cirurgiõesdentistas quanto outras pessoas que estiverem dentro do ambiente clínico podem sofrer microtraumas (9).

Em estudo sobre contagem de manchas de sangue sobre os óculos do cirurgião durante vários procedimentos cirúrgicos, concluiu-se que o uso de turbinas e brocas em cirurgias orais é capaz de produzir um grande número de borrifos de sangue, devido à produção de aerossóis. Tal efeito seria tanto mais pronunciado quanto maior fosse a duração do procedimento cirúrgico. Por esse motivo, recomenda-se o uso de protetores oculares para cirurgias intra ou extraorais (10).
Apesar do conhecimento de que, durante o trabalho do cirurgiãodentista, há dispersão de aerossóis que podem conter microrganismos patogênicos, algumas clínicas odontológicas são projetadas com vários consultórios no mesmo ambiente. Estes consultórios são utilizados simultaneamente por vários profissionais ou alunos, sem barreiras físicas (divisórias) entre eles. O objetivo deste trabalho foi verificar como se dá a dispersão e qual o alcance máximo dos respingos (macropartículas de aerossol) durante atendimentos odontológi$\cos$ nos quais são utilizados instrumentos rotatórios e seringa tríplice; e se a dispersão dos respingos representa perigo de infecção cruzada para profissionais e pacientes em clínicas onde ocorrem atendimentos coletivos.

\section{MATERIAIS E MÉTODOS}

O presente estudo foi realizado em abril de 1995, na Clínica Odontológica da Fundação Benjamim Guimarães (Hospital da Baleia), onde funciona a disciplina de Clínica Integrada de Atenção Primária III da Faculdade de Odontologia da Universidade Federal de Minas Gerais, Belo Horizonte, Brasil. Esta clínica possui 11 equipamentos odontológicos distribuídos em duas salas. O experimento aqui descrito foi realizado em uma sala com cinco cadeiras, posicionadas a uma distância de 1,40 m umas das outras, tomando como referência um ponto no encosto de cabeça das mesmas, equivalente à localização da boca do paciente (figura 1). Os equipamentos possuem recipientes plásticos para a água a ser utilizada na refrigeração da turbina de alta rotação e na seringa tríplice. Estes recipientes comportam $700 \mathrm{ml}$ de água, onde foram diluídos $10 \mathrm{ml}$ de pigmento colorido (anilina). Foi adotada a seguinte ordem de cores: unidade 1, pigmento rosa; unidade 2, pigmento azul; unidade 3, pigmento amarelo; unidade 4, pigmento verde; unidade 5, pigmento marrom.

Papel crepom branco foi utilizado para cobrir todo o piso, cadeiras, equi-
FIGURA 1. Posicionamento e numeração das cadeiras e distâncias máximas percorridas pelos respingos ${ }^{a}$

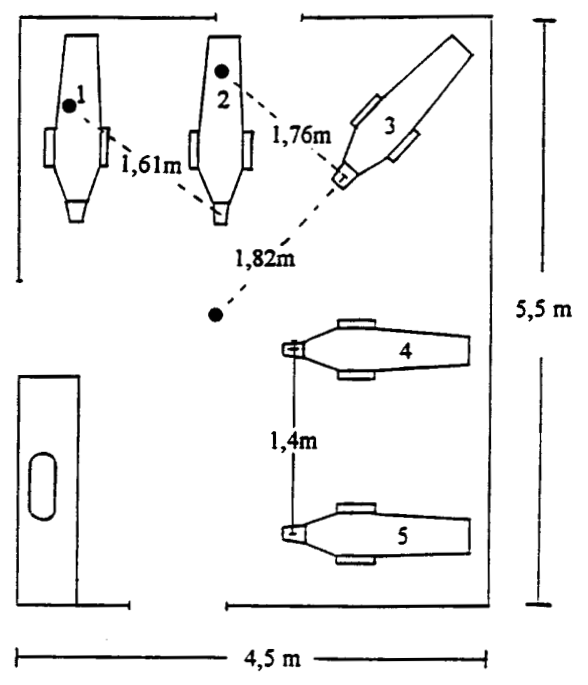

${ }^{a}$ Cor do pigmento em cada unidade de tratamento: 1) rosa 2) azul; 3) amarelo; 4) verde; 5) marrom

- = pontos atingidos pelos respingos que percorreram as distâncias máximas

pos, refletores, braços das cadeiras, canetas de alta rotação e seringas tríplices, com a finalidade de facilitar a visualização dos respingos coloridos. $\mathrm{O}$ operador e o paciente foram paramentados com gorro e avental de mangas longas também de papel crepom branco, com a mesma finalidade. Uma máscara de papel cartão branco cobrindo toda a face e luvas de látex também foram usadas pelo operador. A mesma paramentação foi utilizada durante todo o experimento.

Cinco atendimentos clínicos simulados foram executados por um único profissional em um único paciente, seguindo a seqüência ascendente das unidades de tratamento, com o profissional na posição de 9 horas e o paciente totalmente reclinado. Durante 5 minutos, foi utilizada uma turbina de alta rotação sem broca (por segurança) com refrigeração à água (pigmentada). $\mathrm{O}$ jato foi direcionado para a boca do paciente e o operador procurou atingir as superfícies oclusais e incisais de 
todos os dentes em todos os sextantes. Em seguida, utilizou-se a seringa tríplice, com o jato de água por 1 minuto e o spray ar/água também por 1 minuto, ambos direcionados para a superfície vestibular dos incisivos superiores. O tempo total do atendimento em cada unidade foi de $7 \mathrm{minu-}$ tos, suficiente para esgotar toda a água pigmentada em cada um dos cinco reservatórios. Durante todos os atendimentos, foi utilizada uma cânula plástica descartável de 3,2 mm de diâmetro acoplada a um sugador de saliva de média potência. Portas e janelas foram mantidas fechadas durante os procedimentos, evitando correntes de ar.

Após os cinco atendimentos, três pessoas verificaram, a olho nu, a presença de manchas coloridas em todas as partes que estavam cobertas pelo papel crepom, circulando com caneta azul aquelas mais distantes de seu ponto de origem. Procedeu-se à verificação do alcance máximo dos respingos pigmentados, considerando como ponto de origem uma marca referente à boca do paciente, feita no encosto de cabeça da cadeira cuja água do reservatório tinha a mesma cor do respingo que estava sendo avaliado. A medição foi executada com uma trena, por um único examinador, supervisionado por outros dois. As medidas foram confirmadas por três vezes.

\section{RESULTADOS}

Foram encontradas manchas coloridas no papel crepom colocado no piso, cadeiras, unidades auxiliares, cadeiras vizinhas, hastes e lentes dos refletores e bandejas colocadas sobre os equipos. A distância máxima percorrida por um respingo, capaz de reproduzir, no papel crepom, uma mancha perceptível a olho nu, foi de 1,82 m, em um ponto localizado no piso, atrás da cadeira onde o mesmo teve origem (unidade de tratamento 3). Foi possível determinar o ponto de origem dos respingos através de sua coloração.

Verificaram-se respingos em duas cadeiras adjacentes àquela onde foi feito o atendimento: a cadeira 1 foi atingida por respingo de cor azul, proveniente da unidade 2, alcançando 1,61 m; e a cadeira 2 foi atingida por respingo de cor amarela, proveniente do equipamento 3 , alcançando 1,76 m (figura 1). A maior concentração de respingos se deu no equipamento de proteção individual utilizado pelo operador, principalmente na máscara. Além disso, uma grande concentração de respingos foi observada no gorro, face e avental utilizados pelo paciente. A porção distal da manga do avental utilizado pelo operador também foi muito atingida.

\section{DISCUSSÃO}

Qualquer partícula presente no aerossol, seja de que tamanho for, poderá conter microrganismos patogênicos e causar uma infecção cruzada. No entanto, não foi objetivo deste estudo verificar como ocorre a dispersão de micropartículas, que é mais lenta e mais distante do que a dispersão dos respingos, pois seriam necessárias técnicas especiais de coleta e cultura de microrganismos $(1,5,8,11)$.

O objetivo do presente trabalho foi verificar como se dá a dispersão de respingos produzidos na boca em conseqüência da utilização de turbina de alta rotação e seringa tríplice. Os respingos foram encontrados em todas as direções até uma distância máxima de $1,82 \mathrm{~m}$, semelhantemente ao trabalho de Miller e Micik (12), que registraram uma distância de 2,0 m. Durante um atendimento real e simultâneo em clínicas de atendimento coletivo, as cadeiras vizinhas e seus respectivos pacientes e operadores, bem como as bandejas clínicas contendo instrumental esterilizado, podem estar situados dentro da área de abrangência dos respingos. Portanto, é bastante clara a possibilidade de ocorrer contaminação cruzada quando da execução de tais atendimentos.

Os respingos que se depositaram sobre o operador se concentraram principalmente na região da face, o que está de acordo com resultados obtidos por outros autores $(10,13)$. Isto reforça a necessidade de uso de proteção ocular para evitar a contaminação através desta porta de entrada e também para evitar possíveis lesões traumáticas causadas por fragmentos de restaurações, pontas ativas ou lâminas quebradas de brocas $(7,9,14,15)$. Estes fatos também reforçam a necessidade de implementar medidas obrigatórias de precaução universal e efetivo controle de infecção. O uso de lençóis de borracha e soluções antimicrobianas combinadas com escovação pré-operatória são indicados para reduzir a contaminação bacteriana e sua disseminação (5).

É interessante salientar que uma grande concentração de respingos foi encontrada na porção distal da manga do avental do operador, o que reforça a indicação do uso de avental de mangas compridas. Os resultados encontrados no presente estudo apontam para a necessidade de utilização de equipamentos de proteção individual (5) e para o perigo da realização de atendimentos simultâneos em clínicas coletivas sem interposição de divisórias entre as unidades de tratamento.

\section{CONCLUSÕES}

Conclui-se que há possibilidade de ocorrer infecção cruzada devido à utilização de turbinas de alta rotação e seringas tríplices. Este risco é mais pronunciado quando se realizam atendimentos coletivos e simultâneos, com várias cadeiras no mesmo ambiente, onde os pacientes não estão protegidos pelos mesmos equipamentos que protegem o cirurgião-dentista e ficam vulneráveis à infecção por via conjuntiva ocular e mucosa do trato respiratório. Além disso, as bandejas clínicas com o instrumental a ser usado podem ser atingidas por respingos provenientes de outras unidades de tratamento próximas. Os resultados indicam a necessidade de colocação de divisórias entre equipamentos localizados em um mesmo ambiente. A importância do equipamento de proteção individual para dentistas e assistentes também ficou evidente a partir dos resultados do presente estudo. 


\section{REFERÊNCIAS}

1. Samaranayake LP, Scheutz F, Cottone JA. Controle da infecção para a equipe odontológica. São Paulo: Editora Livraria Santos; 1995.

2. Shovelton DS. Cross-infection in dentistry. J Dent 1980;8:1-2.

3. McCauley KR, Gerbert BJ, Greene JC, Robertson PB, Littlejohn C, Greenspan D, et al. Hazards of occupational transmission and strategies for prevention of infectious disease in dental education. J Dent Educ 1988;52:530-534.

4. Verrusio AC. Risk of transmission of the human immunodeficiency virus to health care workers exposed to HIV-infected patients: a review. J Am Dent Assoc 1989;118:339-342.

5. Bentley CD, Burkhart NW, Crawford JJ. Evaluating spatter and aerosol contamination during dental procedures. J Am Dent Assoc 1994; 125:579-584.

6. Medeiros UV, Riul LF. Riscos ocupacionais do cirurgião-dentista e sua prevenção. Rev Paul Odontol 1994;16:34-43.
7. van Amerongen WE, de Graaff J. Hygiene in dental practice-Part I, Potential pathogens and possibilities of contamination: infection control. J Dent Child 1988;55:47-55.

8. Legnani $\mathrm{P}$, Checchi L, Pelliccioni GA, D'Achille CD. Atmospheric contamination during dental procedures. Quintessence Int 1994;25:435-439.

9. von Krammer R. The dentist's health: highspeed rotary equipment as a risk factor. Quintessence Int 1985:5:367-371.

10. Schnetler JFC. Blood splashes to the eyes in oral and maxillofacial surgery, and the risks of HIV transmission. Br J Oral Maxillofac Surg 1991;29:338-340.

11. Holbrook WP, Muir KF, Macphee IT, Ross PW. Bacteriological investigation of the aerosol from ultrasonic scalers. Br Dent J 1978; 144:245-247.
12. Miller RL, Micik RE. Air pollution and its control in the dental office. Dent Clin North Am 1978;22:453-476.

13. Couto JL, Couto RS, Giorgi SM. Controle da contaminação nos consultórios odontológicos. Rev Gaucha Odontol 1994;42:347-355.

14. Grundy JR. Enamel aerosols created during use of the air turbine handpiece. J Dent 1967; 46:409-416.

15. Hartley JL. Eye and face injuries resulting from dental procedures. Dent Clin North Am 1978;22:505-506.

Manuscrito recebido em 26 de janeiro de 1996. Aceito em versão revisada em 18 de novembro de 1996.

ABSTRACT The professionals and patients involved in dental examinations are at risk for infection by various disease-causing bacteria, viruses, and fungi, such as those responsible for hepatitis, tuberculosis, herpes, and AIDS. It is known that aerosols and spatter containing pathogenic microorganisms can spread during an examination. Nevertheless, some dental clinics are designed to have multiple examination areas in the same room, with no physical barriers between them. The objective of this study was to verify the reach of spatter resulting from the use of a triple syringe and high-rotation turbine during five simulated exams in a collective clinic, bearing in mind that spatter can contain the patient's saliva and blood. To facilitate tracking of the spatter, aniline dye (pink, blue, yellow, green, and brown) was added to the water in the appropriate receptacle in each of the five units. The room, the equipment, and the patient's and operator's clothing were covered with white paper. A high concentration of spatter was observed on the chair, the operator, and the floor of each unit, and it also appeared on the chairs and trays of the surrounding units. The maximum distance reached by spatter was $1.82 \mathrm{~m}$ from a point on the chair corresponding to the position of the patient's mouth. During real simultaneous examinations, the surrounding chairs and their patients and operators, as well as the trays containing sterilized instruments, are within spatter range. Therefore, there is a real possibility of crossinfection, and physical barriers should be placed between the units. This study also confirmed the need for protection of the operator's face, body, hair, and arms, since these regions were heavily affected by spatter. 